\title{
Retraction Note to: A Case for a Limited Breeding Exemption from Patent Protection
}

\author{
Zhiqian Wan · Samuel Meng
}

Published online: 19 December 2018

(C) Max Planck Institute for Innovation and Competition, Munich 2018

\section{Retraction Note to: IIC (2018) 49:636-655 \\ https://doi.org/10.1007/s40319-018-0719-x}

The Editors-in-Chief have retracted this article ("A Case for a Limited Breeding Exemption from Patent Protection" by Zhiqian Wan and Samuel Meng, IIC (2018) 49:636-655, https://doi.org/10.1007/s40319-018-0719-x) because the article shows significant overlap with two previous publications by Viola Prifti without proper citation ("The Breeding Exemption in Patent Law: Analysis of Compliance With Article 30 of the TRIPS Agreement" by Viola Prifti, The Journal of World Intellectual Property (2013) Vol. 16, No. 5-6, pp. 218-239, https://doi.org/10.1002/jwip. 12014 and "The Breeder's Exception to Patent Rights - Analysis of Compliance with Article 30 of the TRIPS Agreement" by Viola Prifti, Springer 2015, ISBN 978-3-319-15770-2, https://doi.org/10.1007/978-3-319-15771-9). Authors Zhiqian Wan and Samuel Meng do not agree to the retraction."

The original article can be found online at https://doi.org/10.1007/s40319-018-0719-x.

\section{Z. Wan}

Associate Professor; College of Humanity and Law, Huazhong Agricultural University, Wuhan, China

e-mail: 35606263@qq.com

S. Meng ( $ه)$

Senior Research Fellow; University of New England Business School, Armidale, Australia e-mail: xmeng4@une.edu.au 